\title{
Alfred de Musset, La Confession d'un enfant du siècle
}

\section{Valentina Ponzetto}

\section{(2) OpenEdition}

\section{Journals}

\section{Edizione digitale}

URL: http://journals.openedition.org/studifrancesi/5687

DOI: 10.4000/studifrancesi.5687

ISSN: 2421-5856

\section{Editore}

Rosenberg \& Sellier

\section{Edizione cartacea}

Data di pubblicazione: 1 septembre 2011

Paginazione: 438

ISSN: 0039-2944

\section{Notizia bibliografica digitale}

Valentina Ponzetto, «Alfred de Musset, La Confession d'un enfant du siècle», Studi Francesi [Online], 164 (LV | II) | 2011, online dal 30 novembre 2015, consultato il 07 janvier 2021. URL: http:// journals.openedition.org/studifrancesi/5687 ; DOI: https://doi.org/ERREUR PDO dans /localdata/ www-bin/Core/Core/Db/Db.class.php L.34 : SQLSTATE[HY000] [2006] MySQL server has gone away

Questo documento è stato generato automaticamente il 7 janvier 2021.

\section{(c) (i) (9)}

Studi Francesi è distribuita con Licenza Creative Commons Attribuzione - Non commerciale - Non opere derivate 4.0 Internazionale. 


\title{
Alfred de Musset, La Confession d'un enfant du siècle
}

\author{
Valentina Ponzetto
}

\section{NOTIZIA}

ALFRED DE MUSSET, La Confession d'un enfant du siècle, présentation et notes par sylvain LEDDA, Paris, Flammarion, 2010, 362 pp.

1 La Confession d'un enfant du siècle è al tempo stesso una sorta di autobiografia romanzata, che intrattiene molteplici quanto ingannevoli legami con le esperienze di vita dell'autore, e il ritratto lucido e disincantato di un'epoca e di un'intera generazione nata sotto il primo impero, che non a caso si può definire con José Luis Diaz «génération Musset».

2 Nato dall'esperienza della relazione con George Sand, dal trauma dell'avventura veneziana e dal successivo scambio di lettere della primavera 1834, biografemi rapidamente evocati da Sylvain Ledda nella sua presentazione, il romanzo non può tuttavia ridursi ad una trasposizione narrativa del «drame de Venise», poiché, come sottolinea giustamente il critico, lungi dal limitarsi ad un'autopsia del proprio cuore, Musset solleva questioni più universali sulla natura umana e la morale, la ricerca della verità e il bisogno di redenzione e rigenerazione.

3 Del resto la tradizione letteraria passata e contemporanea costituisce una rete di riferimenti e fonti di ispirazione importanti almeno quanto l'esperienza vissuta. Sylvain Ledda analizza dapprima il rapporto del romanzo con la tradizione delle Confessioni: quelle di Sant'Agostino, padre fondatore del genere e modello esplicitamente rivendicato, a cui rimandano chiaramente la riflessione sulla problematica del Male e le frequenti invocazioni a Dio, malgrado lo scetticismo quasi ateo del protagonista; e naturalmente quelle di Rousseau, per cui Musset nutre al tempo stesso ammirazione e disgusto in virtù dell'impudica schiettezza che le caratterizza. 
In un secondo tempo è il rapporto con i contemporanei a venire interrogato. Nell'ambito della voga romantica per il «roman-confession» e il «roman intime» così come descritto da Sainte-Beuve in un articolo del 1832 sulla Revue des Deux Mondes, la Confession d'un enfant du siècle è accostata a Volupté dello stesso Sainte-Beuve, Arthur d'Ulric Guttinguer, René, Obermann, Lélia e Adolphe. Sylvain Ledda sottolinea come Musset si inserisca nel cuore delle problematiche del suo tempo, in particolare per la definizione e l'incarnazione esemplare in Octave de $\mathrm{T}^{* * *}$ del «mal du siècle», fatto di malinconia, noia, pessimismo, disincanto, vana rivolta, ripiegamento dell'eroe su se stesso e sacralizzazione delle sue sofferenze d'amore. Tuttavia Musset va oltre i suoi contemporanei e immediati predecessori nella sua volontà di legare microcosmo $\mathrm{e}$ macrocosmo, l'autopsia di un'anima e di una passione e l'affresco di un'epoca minata da un senso di disperata disillusione politica e di fallimento della Storia. Romanzando e storicizzando la sua esperienza personale, Musset presenta al lettore un'inquietudine generazionale, tanto più tragica in quanto descritta senza concessioni fin dall'apertura del romanzo, chiaro segno che le vicissitudini del protagonista non possono che concludersi su un fallimento e che, a differenza degli eroi di Sainte-Beuve e Guttinguer, ogni redenzione è per lui impossibile.

5 Infine il critico rileva nel romanzo alcuni elementi della poetica di Musset: il ritorno ciclico di temi e immagini, in particolare erotiche e macabre, l'alternanza di racconto e discorso analitico, una struttura tesa fra slancio lirico spesso anche enfatico e armonia classica incisiva ed elegante, una retorica e quasi una prosodia prese in prestito alla letteratura religiosa per elevare il dolore e l'amore al rango del sacro, l'onnipresenza del tema della morte - di cui Sylvain Ledda è del resto un grande specialista, avendogli consacrato la sua tesi di dottorato («Des feux dans l'ombre». La Représentation de la mort sur la scène romantique) - dal lutto collettivo di una generazione orfana di Napoleone, a quello privato della morte del padre, alla morbosità di un Eros più che mai sotto il segno di Thanatos. «Musset - conclude il critico - brosse le tableau des vanités de son siècle. De tous les siècles: perte des valeurs, absurdité de la condition humaine, échec inévitable de l'amour».

6 Per quanto riguarda i criteri d'edizione, il testo riproduce quello originale e integrale del 1836, ma segnala fra parentesi graffe i passaggi soppressi nell'edizione del 1840 perché considerati troppo violenti o passionali, seguendo la via già tracciata da Paul de Musset nella sua edizione del 1866 detta «Aux amis du poète» e generalmente ripresa dalle migliori edizioni moderne. 